\title{
The Motivation of Problem-Based Teaching and Learning in Translation
}

\author{
Zheng Yingxue ${ }^{1}$ \\ ${ }^{1}$ Department of Foreign Language, Guangzhou Pearl-river Vocational College of Technology, Guangzhou, China \\ Correspondence: Zheng Yingxue, No. 2 Tashan Road Zengjiang Street of Zengcheng District, Guangzhou \\ 511300, China. Tel: 86-135-3512-6494. E-mail: 13535126494@139.com
}

Received: January 29, 2013 Accepted: March 7, 2013 Online Published: March 20, 2013

doi:10.5539/elt.v6n4p120 URL: http://dx.doi.org/10.5539/elt.v6n4p120

The research is financed by China's guangdong province department of education teaching reform project, No. 20120202086, Type B.

\begin{abstract}
Problem-Based Learning (PBL) has been one of the popular pedagogical strategies these years. PBL is about students connecting displinary knowledge to real-world problems - the motivation to solve a problem. To cognize general elements and typological differences of language in translation is the motivation to solve real problems such as diction, grammatical construction, style and culture, conversion etc, which is the most creative pointview in PBL teaching and learning of translation.
\end{abstract}

Keywords: Problem - Based learning and teaching, general elements, typological classification of languages; translation

\section{Introduction}

Problem-Based Learning has been one of the popular pedagogical strategies those years. In a problem-based learning (PBL) model, students engage complex, challenging problems and collaboratively work toward their resolution. PBL is about students connecting disciplinary knowledge to real-world problems - the motivation to solve a problem becomes the motivation to learn.

Translation in teaching also can begin with the problems such as diction, grammar, construction and cultural habit ect. But the difficulties are how to design the problems from different angles. For translation problems in teaching, translator as a speaker can explain the source language in detail in the target language. In the second language learner and the teacher's minds, there's a speaker supposed, which is regarded as the angles of teaching and learning. From a philosophical angle to teach and learn translation, those problems can be settled out.

Translation is a very difficult activity, just like what Luxun, a famous writer in $20^{\text {th }}$ century, has said, "I always consider that translation is easier than creative work, since at least, in the forever there's on need to conceive plots. However, as soon as I touch translation, encounter some obstacle. For example, in case you fail to write out a necessary noun or verb, you can avoid them in creation, but you can't do so in translation. In translation you must go on pondering until you feel dizzy, as if you're searching for a key to a boy, you want badly but in vain. Yan Youling once said. "Setting up of a new name in translation would name in translation would make you hesitating for ten days or a month". It is their own experience. It is true in every sense of the words which are the reflections of the problems mentioned above. But if the students master the general elements and the (typological) difference among languages, a set of advanced theories are required. Translation is a linguistic activity to transform the content of a source language into that of target language fully and perfectly.

So far on the earth there are about 4500 or 6000 different languages being used. Many linguists believe that general elements (Note 1) in different language are to form syntax functions and it is their difference s that should be remembered by translators. The universal things existing in different societies and on the earth lead to the semantic translatability (Note 2) of different languages. The different things existing in different people and on earth lead to the untranslatability. The general elements of language refer to the same or similar existed grammatical categories in Chinese and foreign languages. According to the grammatical phenomena and structures, languages are classified into different types. The difference in language is because of the different 
existed objective things including geographical feature, the materials, the history and social structure and so on, which lead to the classification of language in linguistic.

Language is a system of signs. Different languages have different systems of signs. Because the relationship between similarly and Difference of language effecting on translation, we consider the effect of general elements and difference of language on translation in terms of meaning and grammatical categories, which can be regarded the most effective method to teach and learn translation.

\section{The General Elements and Classification of Languages}

In order to settle out the problems in translation, it's very necessary to master the general elements and classification differences between the source language and the target language.

What are the general elements (Claude Hagege, 1985) in different languages?

Human beings possess the endowment of acquiring languages. The acquisition of language needs flexible articulatory organs can produce speech sounds, a highly developed brain can generalize, judge, reason all the abstract behaviors. The average people who speak various languages just all have these functions in their body, so all the languages have general elements which mainly are embodied in the respects of speech sounds and grammatical categories. Just because of these common characteristics, in different languages there is translatability. A good example is Chomsky (Note 3)'s TG.

In western linguistic history, Chomsky's TG, actually is to find the universal grammar (N. Chomsky, 1965) in languages. He found the common things in people's mind. For example, parts of speech and their related grammatical functional elements. But Chomsky can't explain parole, phenomena of particular language. Halliday explains this phenomenon from the angle of social function.

The greatest relations of the translation with general elements of languages are embodied in cognitive categorization - parts of speech in grammar. Like English in Chinese grammar there are also parts of speech - noun, verb, adjective adverb and particular instances of translation and translations embody how these categories of two languages relate to one another. Since translation has to do with language, the analysis and description of translation-processes must make considerable use of categories set up for the description of languages. For example, the greatest contrast between Chinese and English is in the grammatical system. The sentence “China has a long history" is translated into “中国具有悠久历史。” The sentence “Chinese people is a great people” is translated into “中国人民是一个伟大的民族。” These sentence orders between English and Chinese are same. In the translation of these two languages the grammatical categories correspond to each other. In this case, the direct way of translations should be adopted

The conceptual level is also translatable (Susan Bassnett, 2002): an event occurring in pastime is being reported in present time. The difficulty of the problems concerns the translation of gramaticalization, for example, translation of the noun of English phrases into the verb in Chinese. Direct translation is the way to translate the general meaning elements by keeping the original style and the structure

\section{General Elements and Typological Classification (Note 4) of Language in Translation}

In reality, however, a proper theory of translation can mean freedom to produce meaningful result for a theory explores the "why" and "how" of translation and not merely the "what" This means generally discovering the balance between content and form.

In translation, the incompatibility between content and form is mainly caused by the different historical culture leading to different linguistic signs and signifiers. But man can overcome this different, because every normal man has linguistic competence. Linguistic competence is a native speaker's linguistic knowledge of his language. This knowledge allows him the potential ability to understand and produce sentences produce sentence or utterances which has never heard of or produced. A native speaker knows what sentences are grammatical and what sentences are ungrammatical. Such linguistic competence is not postnatal but inmate, so if a Chinese wants to master English, he must master the linguistic knowledge. As a super good translator, he must master am advanced translation theory. Creative use of language is part of human beings ' linguistic competence. Chinese learner should use our ability of acquiring language and creatively using language. Now our problem focuses on "How would Chinese acquire English by the advanced teaching way?"

How a speaker use native language is his language behavior which is also called linguistic performance. Linguistic performance is the actual use of one's linguistic knowledge or competence in different situations or contexts. Linguistic performance may vary from speaker to speaker due to various factors. One can learn a language if he lives in the given environment. Linguistic competence and performance are not identical. The 
relation between the two just like "knowing something" is not the same as "doing something". Linguistic competence underlies linguistic performance, which is embodied in translation. Thus Chinese learners should develop their linguistic competence so that their English performance in translation approaches the native speaker.

English history is divided into three periods of old English, middle English and modern English. Old English was the language spoken by Saxons, Angels, and Jutes after they settled on the British Islands. They came to the islands and brought with them their dialects of the Germanic language, which were closely relate to each other from the Great North Germanic plain in 449A.D. Since then they thought themselves as Englishmen. Thus the old English period began with the Norman Conquest of England by Northman under the leadership of William the Conqueror, who defeated King Harold II at the battle of Hastings in 1066. It lasted for over four centuries, and was followed by the Modern English period which is related to that of Middle English by the Renaissance, After the death of Chaucer. The language saw greater and more important phonological lexical and syntactic changes than in any other centuries before or after. Chinese modern history is different from English modern history. Chinese feudal society lasted thousands of years so that the cultural consciousness is different. Because of English Mechanical Industrial Movement in English countries science is more advanced than in China.Chinese fell behind England and America scientifically, politically, economically, which lead to the linguistic mental difference. For example, ever since the early 1970s along with the disclosure of the notorious political dubbed as Watergate event, a bunch of derived words have been rushing into the English language. Words like "Billgate" "Debategate" "Cattlegate" "Ricegate" are some of gate these compounding forms. In this situation, it is felt that a sociolinguistic study of the combining from of gate and its derivations is necessary for us to examine the semantic structural and functional development concerning these gate-words and know more about the correlation of these related factors in of word formation. After a careful study of this phenomenon, we found that 1) this suffix enjoys rich productivity in American English; 2) words derived from this source inevitably take on culturally pejorative implication to refer to "the disclosures of misconduct in high places" hence, a synonym to scandals of different types, political or economical and 3) a variety of derivational processes can be explained in the study of the productivity compounding form Based on these findings, we can draw some tentative conclusions. a) Watergate as a word taking on a pejorative implicature to any political scandal at the high rank, will stay in English for quite a long time.

This compound has become so generalized in its from and and meaning that some gate word have even gone out of the American society and been used to refer to political scandals in other cultures as well. As this word shows, language and culture are correlated with each other at different levels of linguistic structure, so this word is translated into “水门”, while in Chinese there's on this word,so there is there is the way of free translation, namely translation by meaning is the way to translate the chief meaning of the original text.

Another example, in Chinese-English intercultural communication, kinship terms often are recognized as problems because equivalents are not always existed. The statement "Lindas brother married Michael's sister" is not easy render into Chinese without further information about whether the brother is older or younger than Linda and whether the sister Michael's elder or younger sister. The reason is that in Chinese there are very rich terms to designate specific relationships respectively like the following table.

Table 1.

\begin{tabular}{llll}
\hline Chinese & \multicolumn{1}{c}{ the first address } & the second address & the third address \\
\hline 祖父(母) & Paternal grandfather(grandmother) & grandfather(gandmother) & \\
外祖父(母)maternal grandfather(grandmother) & $\begin{array}{l}\text { grandfather(gandmother) } \\
\text { parents }\end{array}$ & \\
父母 & father, mother & brother & \\
兄弟 & elder brother, younger brother & sister & \\
姐妹 & elder sister, younger sister & elder brother & uncle \\
伯父 & paternal uncle(father's brother) & younger brother & uncle \\
叔父 & paternal uncle(father's brother) & uncle & \\
姑父 & husband of father's sister & mother's elder brother & uncle \\
舅父 & maternal uncle & husband of father's sister & uncle \\
姨父 & maternal uncle & brother-in-law & \\
姐夫 & husband elder sister & brother-in-law & \\
妹夫 & husband younger sister & & \\
\hline
\end{tabular}


The above chart shows the complicated relationship contrast between Chinese kinship and English kinship.

Equivalence in translation then should not be regarded as a search for sameness, since sameness cannot even exist between two different language of the died cultural background. Equivalence is problem of translation. we need not go further into such distinction as 姨公(婆) mother's sister and father's sister, 堂(表)兄弟 mother's cousin and father's cousin，嫂子 sister-in-law，弟妹 younger sister，小舅子 wife's brother，侄子 cousin，外甥 nephew and so on.

Above all, finding equivalent words in translation is always to deal in the usual different ways of the same things.

Linguistic untranslatability is due to oxymoron between the cultural and the translation, while cultural untranslatability is due to the absence in the translated culture of a relevant situational feature for original text (Deng Yancang, Liu Runqing, 1989). Now quote the example of the different concepts of the term bathroom in an English, Finnish or Japanese context, where both the object and the use made of that object are not at alike. But more abstract lexical items such as the English term home or democrat cannot be described as untranslatable, and the English phrases I'm going home, or He's at home. can not be provided with translation equivalents in most languages, and the term democrat is international instead.cultural untranslatability must be (effectors) implied in any process of translation. For example, the translation of idioms takes us a stage further in considering the question of meaning and translation, for idioms, like puns, are culture bound. Take the following translation as examples

\section{1 换汤不换药}

the same medicine with a different name (direct translation)

a change in from but not in content (translation by meaning)

王小二过年,一年不如一年

Things are going from bad to worse for company with each passing year.

The financial situation of the company is deteriorating in recent years.

解铃人还需系铃人

Let him who tied the bell on tiger, take it off.

Whoever stated, the trouble should end it.

千里之堤, 溃与蚁穴

One ant-hole may collapse of thousand li dyke.

Slight negligence may lead to great disaster.

2 一部西部牛仔片

特洛伊木马

阿基里斯的脚踵

悬挂在达摩里斯头上的剑

3 门户开放政策

最优惠国条款

实力地位政策

4 与对象国的固定交往

运煤到纽卡索, 多此一举

红白喜事

黄色书

黄色电影 a horse opera

the Trojan horse

the heel of Achiles

the sword of Damocles

the open-door policy

the most-favored nation clause

the position-of-strength policy

go steady with

to carry colas so Newcastle

wedding and funerals

filthy book

obscene movies

By the first and the fourth groups of example, these proverbs in Chinese are translated into English by the direct translation, which can not be understood by the native speaker. But the sentences describe the same social existence which can not be understood by the translating way of meaning, so the first group is translatable. The second and third groups are untranslatable. The second groups of English-Chinese example are only existed in English history while there's no equivalent in English. But the first and the fourth groups of example are 
translatable though proving the problems of equivalents. The question of the differences between the Chinese and English languages is a very big subject. To venture into this field one has to be rather good at both languages, good in the sense of not only having a good practical command but also having a good knowledge of linguistics.

Just like the English philosopher Wilgenstein puts it, "The meaning of a word is its use in the language."

Because of these different of historical culture, linguists classified the languages into different types. Considering the grammatical difference, we call the typological classification of languages the morphological classification. The languages of the world are usually classified into four types: isolating agglutinating, inflectional and polysynthetic (Hu Zhuanglin, 2001).

(1) Isolating language, which are also called root languages, are characterized by the relationships between words and other grammatical relations indicate by function words order than by internal inflectional;

(2) An agglutinative language is which combines into a single word various linguistic elements or morphemes with each having a distinct and fixed grammatical meaning and a separate existence. Take Turkish for example, the word for "teeth" "is" "dis" and the word for "house" is "ev".

An inflectional is a language in which a word undergoes a change in morphological form when its grammatical function in the sentence is changed. Inflectional morphemes are added only to lexical stems, but these added inflectional morphemes fuse with the stem and have on independence. Old English was also highly inflectional. Middle English lost many inflectional endings.

A polysynthetic language is language in which a number of word elements are joined together to form a composite word that functions as a sentence does in the language of other types, in America Indian language the main verb is usually the core of a sentence, with all other elements (or morphemes) indicating different grammatical meanings attached to it.

Chinese is usually considered as a typical isolating language, characteristic of derivational and inflectional morphemes. Derivational and inflectional affixes are virtually nonexistent in Chinese. Verbs are never inflected for person, number, number, tense, aspect, mood or voice, as in 你 you (我 I, 他 he, 你们 you, 我们 we,他们 they) 看书 read books----and nouns for number, gender or case as in 一(两 two, 三 three) 本书 books, 我 my (她 her)的书 and prefixes or suffixes are rarely found. English is partially isolating, for it has thousand of free morphemes that stand by themselves as independent word such as in, book, fast, he, speak, and so on, and it express future tense by means of the word will and shall, or by other periphrastic means, rather than by the inflection of its word E g. Modern English is to some extent agglutinative and inflectional, but on the whole, it is more isolating than inflectional or agglutinative. Therefore, typological classification of languages is relative rather than absolute. A language may possess more characteristics of one type of language than those of other types.

This typological classification can mainly instruct the translation on English tense. For example, the third person-s is translation into Chinese subject 他 he, 她 she, 它 it, as soon as you see the -s following the predicate verb.Another example, as soon as you see in Chinese (过去) formerly, (那时) then, (那年) that year,you must add -ed onto predicate verb of English in translation. The translation methodology is the combination of lexical meaning and grammatical meaning in mind. This classification is a way of translation in terms of from.

Syntactic classification is a key to translation in term of grammar. According to syntactic characteristics, language of the world can be classified into two types: synthetic and analytic.

A synthetic language is a language in which grammatical relationships between word are shown principally by inflections and the close merging of affixes with the base or root such as old English.

An analytic language is a language in which grammatical relationships between words or any constituents are expressed principally by means of word order and function words.It is word order and function words that show the logic deep meaning of language. Then the logic meaning again instruct the translations of target language between different languages. Chinese is an analytic language. Modern English, probably more than half, is analytic. As two analytic languages, the common characteristics between them make the translatability between the two languages

\section{Significances in Translation}

For what we discussed above, the general elements have translators adopt the way of direct translation. The typological classified languages have translators adopt the way of free translation. According to these ways, we can freely use transference, translation addition, repetition, omittence of ways and so on. The analysis of general elements and differences between Chinese and English effectively instruct the translation which plays an 
important an important role in teaching and application of computational linguistic in translation, the word order and functional words can freshly embody the logic relations. The logic relations of source language must be embodied in the translations of target language, Chinese syntax is parataxis (意合法) focusing on meaning and time sequence of effect English syntax is hypotaxis centered by function words. For example,

There are many people who want to see the film 许多人看这部电影

Please turn off the light when you leave the room 离屋时请关灯

From these two sentences we can conclude that there are different sentence orders and logic relations

Up went arrow into the air 箭嗖的一下窝向天空

In this sentence the second action happens in the course of the first action. In translations do the general elements between two languages make target language translatable. And according to the classification of languages we can solve the problems of untranslatability. If a language is purely isolating or analytic, its words consist of a single morpheme. Chinese is an isolating and analytic language. English is half isolated and more than half analytic. This classification of common characteristic is contributed to summarizing the translation methodologies.

\section{Conclusion}

To sum up, whatever, in terms of the whole and the part, the general elements or the differences of types of translation affect the motivation teaching theories or learning methodologies in translation.

A famous person for inquiry learning is John Dewey (Note 5). Dewey's philosophy of education, instrumentalism (also called pragmatism), focused on learning-by-doing rather than rote learning and dogmatic instruction. Deway called for education to be grounded in real experience. In real world the students and the teachers should use the idea of general elements and typological classifications to settle out the problems in translation.

\section{Acknowledgements}

Grateful acknowledgement is made to my supervisor Mr.Yin Tiechao who gave me considerable help by means of suggestion, comments and criticism. What's more, I would like to express my gratitude to our college vice-president Mr. Qin Jiajun and our chairman of the board Mr. Wen Zhiming who will give finance support for this thesis. In addition, I deeply appreciate the successful contribution to this thesis in the journal of English Language teaching.

\section{References}

Claude Hagege. (1985). L'Homm De Paroles. Ouvrage publie avec le concours du ministere francais des Affaires Etrangeres.

Deng Yancang, \& Liu Runqing. (1989). Language and Culture. Shanghai Foreign Language Education Press.

Hu Zhuanglin. (2001). Linguistics: A Course Book. Beijing University Press.

N. Chomsky. (1965). Aspects of the Theory of Syntax. Cambridge: MIT Press.

Susan Bassnett. (2002). Translation Studies. London: Routledge.

\section{Notes}

Note 1. General elements refer to the research on the intercommunity in different languages such as transform-generation grammar.

Note 2. the possibility to translate.

Note 3. Chomsky, one of the $20^{\text {th }}$ century's linguists, born in Philadelphia, Pennsylvania in 1928, his philosophy of language is the universal properties of language and the study of meaning. He holds that the aim of studying linguistic competence is to establish a generative grammar.

Note 4. Typological Classification of Language refers to the classification of languages based on the general elements of the intercommunity in different languages. Languages are classified into the types of inflectional language, agglutinative language and isolated language.

Note 5. John Dewey (1952) was an American philosopher, psychologist, and educational reformer whose ideas have been very influential to education and social reform. He is recognized as one of the founders of the philosophy of pragmatism and of functional psychology. He was a major representative of the Progressive education during the first half of the 20th century in the US. 